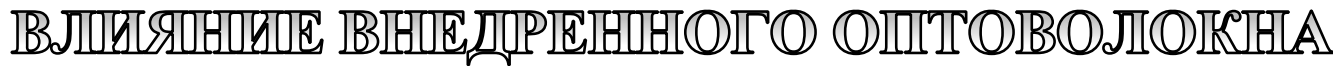

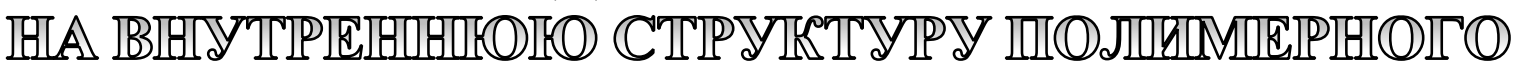

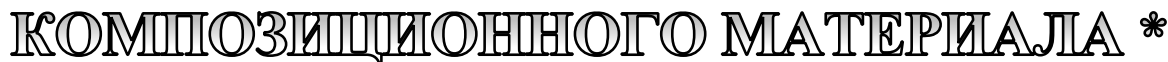

\author{
Н.А. Кошелева, Институт механики сплошных сред УрО РАН \\ Г.С. Сероваев, Институт механики сплошных сред УрО РАН
}

\section{Для цитирования:}

Кошелева Н.А., Сероваев Г.С. Влияние внедренного оптоволокна на внутреннюю структуру полимерного композиционного материала // Вестник Пермского федерального исследовательского центра. - 2021. № 1. - C. 54-63. https://doi.org/10.7242/2658-705X/2021.1.5

В работе исследуются образцы из полимерных композиционных материалов с внедренными оптическими волокнами. Диаметр оптического волокна сопоставим с толщиной слоя композитного материала и при внедрении возможно искажение внутренней структуры исходного материала в окрестности оптоволокна, а следовательно, формирование технологических десектов, представляющих опасность для целостности материала. В исследовании получены микроснимки поперечных сечений для разных типов композитных материалов в окрестности внедренного оптического волокна. Для однонаправленного композитного материала подтверждено фрормирование смоляного кармана при внедрении оптического волокна перпендикулярно направлению армирующих волокон и его отсутствие при внедрении оптического волокна параллельно направлению укладки армирующих волокон.

Анализ снимков тканых полимерных композиционных материалов с саржевым переплетением не выявил существенных искажений внутренней структуры материала. Даны рекомендации по предварительной обработке (полировке) поверхностей образцов из стекла и углепластика. В отличие от известных результатов о существенном влиянии схемы укладки слоев на эфффективность встраивания оптических волокон в композитные материалы, полученные в настоящем исследовании данные свидетельствуют также о влиянии материала армирующих волокон и типа армирования на качество встраивания оптических волокон. Данные фракторы следует учитывать при проектировании и создании конструкций с внедренными волоконно-оптическими датчиками.

Ключевые слова: полимерный композиционный материал, оптическое волокно, волоконно-оптические датчики деформации, микроструктура, смоляной карман.

* Статья подготовлена при финансовой поддержке гранта РФФИ №17-41-590684 p_yрал_a) «Моделирование влияния на механические характеристики SMART-материалов встроенных актуаторов из пьезоматериалов и оптических волокон». 


\section{Введение}

Волоконно-оптические датчики деформации открывают новые возможности, связанные со встраиванием датчиков в материалы на стадиях технологического процесса изготовления материалов и последующим измерением деформаций. $\mathrm{C}$ точки зрения технологии встраивания в материал оптического волокна наиболее перспективными являются полимерные композиционные материалы (ПКМ).

При реализации задачи использования встроенных в материал датчиков возникает ряд проблем. Встроенные в материал оптические волокна и связанные с ними технологические дефекты могут отрицательно влиять на общую прочность и жесткость контролируемого объекта и вызывать опасные локальные концентрации напряжений и деформаций. Согласно существующим исследованиям, влияние встроенных оптических волокон существенно различается для различных видов композитных материалов, типов внешней нагрузки, ориентации встроенного оптического волокна по отношению к армирующим волокнам и направлению нагрузки. При статических нагрузках обычно наблюдается незначительное изменение жесткости композиционных материалов с внедренными оптоволокнами [1-3]. Снижение прочности наиболее заметно при сжимающих нагрузках по сравнению с растягивающими нагрузками и при расположении оптического волокна перпендикулярно направлению нагрузки. Большее негативное влияние встроенных оптоволокон на прочность композиционных материалов наблюдается при усталостных и ударных испытаниях [4-6].

Несмотря на малые размеры, диаметр оптического волокна сопоставим с размером слоя композитного материала и при встраивании может вызвать искажение структуры слоев. В процессе изготовления композитного материала данная область вокруг оптического волокна заполняется эпоксидной смолой. Такой технологический дефект по форме напоминает глаз и в литературе носит назва- ние «смоляной карман» [7]. Размер и форма кармана из смолы определяются многими факторами, главным из которых является ориентация оптического волокна относительно армирующих волокон [8]. Среди других факторов - механические свойства композитного материала, толщина слоя, количество и последовательность укладки слоев, размер оптического волокна, давление отверждения и т.д.

В исследовании [9] предложен подход к определению формы смоляного кармана, основанный на численном конечноэлементном моделировании процесса прессования слоев в плоскодеформированной постановке задачи теории упругости. Проверка полученных численных результатов на реальных изображениях поперечного сечения образцов полимерного композиционного материала (ПКМ) с внедренным оптоволокном показала надежность данного метода определения формы смоляного кармана. Численное исследование влияния встроенного оптического волокна на локальную концентрацию напряжений выполнено в [10]. Авторы предложили описание механизма разрушения под действием растягивающих и сжимающих нагрузок, которое начинается в области смоляного кармана. В [11] изучалось влияние геометрии смоляного кармана, вызванного введением микрососудистого капилляра в стеклопластик, на концентрацию напряжений и распределение напряжений во время разрушения композитов с двумя типами укладки $[0 / 90]_{4 \mathrm{~s}}$ и $[90 / 0]_{4 \mathrm{~s}}$. Экспериментальные исследования, демонстрирующие значительную концентрацию деформаций вблизи встроенного оптического волокна, описаны в $[12,13]$.

Помимо вопросов, связанных с влиянием встроенных оптических волокон на принимающий материал, первостепенное значение имеет проблема надежных измерений деформации. Исследование передачи деформации от материала к встроенному оптическому волокну с использованием матрицы переноса деформации выполнено в [14]. Также известно, что отражен- 
ный оптический сигнал волоконно-оптических датчиков (ВОД) на основе брэгговских решеток искажается при поперечных нагрузках [15-18] и неравномерном распределении деформации по длине решетки [19-21]. Проблема надежного измерения деформаций встроенными оптическими волокнами, вопросы выбора модели, связывающей деформацию оптического волокна в области волоконной брэгговской решетки с измерением ее резонансной длины волны и проблема калибровки, а также частные практические задачи измерения деформаций композитных материалов с помощью волоконно-оптических датчиков обсуждаются в [22-25].

Большинство известных исследований сосредоточено на проблемах, возникающих при встраивании оптических волокон в слоистые композитные материалы с однонаправленной структурой армирования. Для таких материалов хорошо известен и экспериментально подтвержден факт зависимости внешнего вида и размеров смоляного кармана от ориентации встроенного оптического волокна по отношению к направлению армирующих волокон. Однако исследований по внедрению оптических волокон в композиционные материалы, имеющие отличную от однонаправленной структуру армирования, недостаточно.

В данной работе исследованы слоистые композиционные материалы с тканой армирующей структурой. Введение такого постороннего предмета, как оптическое волокно, между слоями этого типа композитных материалов может по-разному влиять на искажение соседних слоев в области оптического волокна из-за другой внутренней структуры. В рамках работы были изготовлены образцы из стекло- и углепластика с внедренными оптическими волокнами. С помощью цифрового микроскопа были получены изображения поперечных сечений изготовленных образцов. Данные образцы позволили проанализировать структурные искажения рассматриваемых типов композиционных материалов, вызванные внедренным оптическим волокном.

\section{Исследование внутренней структуры слоистого ПКМ}

Экспериментальные исследования внутренней структуры композитных образцов из угле- и стеклопластика с внедренным оптическим волокном основаны на изучении поперечных срезов при помощи оптического микроскопа КН-7700, позволяющего получить увеличение до 7000x. Несмотря на имеющиеся в литературе данные $[9,10,26]$, касающиеся образования смоляного кармана в однонаправленных композитных материалах при встраивании оптического волокна, анализ появления смоляного кармана в однонаправленных образцах из углепластика: с направлением армирования вдоль оптического волокна и поперек, необходим, так как вероятность возникновения, размер и форма данного технологического дефекта зависят не только от ориентации слоев относительно оптического волокна, но и от технологии изготовления слоистого композитного материала (вакуумная инфузия, автоклавное формование, прямое прессование). Таким образом, анализ внутренней структуры композитного материала в окрестности встроенного оптического волокна проведен для следующих типов армирования (рис. 1): однонаправленного слоистого композитного материала с направлением армирования вдоль оптического волокна $\left[0_{2} / \mathrm{OF} / 0_{4}\right](a)$; однонаправленного слоистого композитного материала с направлением армирования поперек оптического волокна $\left[90_{3} / \mathrm{OF} / 90_{3}\right]($ б); композитного материала из угле- и стеклопластика саржевого плетения 2/2 (в).

При создании полимерного композиционного материала с внедренным оптоволокном важным является обеспечение целостности волокна в процессе изготовления материала, а также четкое соблюдение всех параметров технологического процесса: давления, температуры и времени, зависящих от марки материала. Процесс внедрения оптического волокна в композитный материал включает в себя ряд основных операций. На первом этапе производится раскрой армирующего мате- 


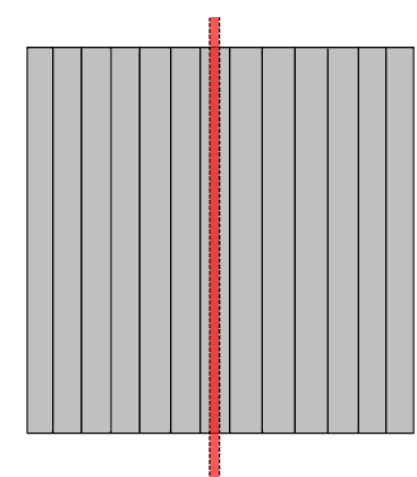

$a$ $\left[\mathrm{O}_{2} / \mathrm{OF} / \mathrm{O}_{4}\right]$

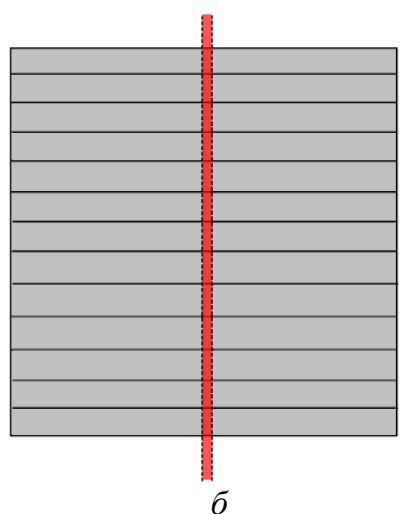

$\left[90_{3} / \mathrm{OF} / 90_{3}\right]$

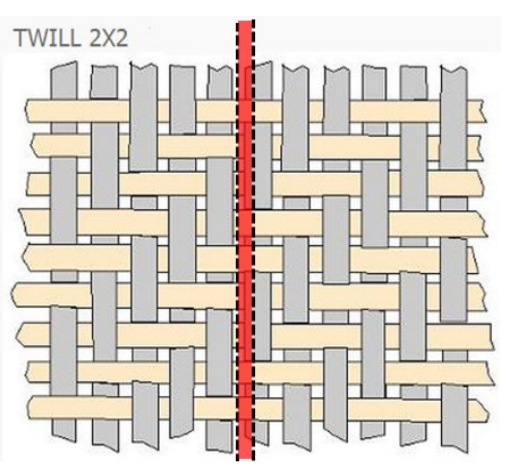

B

саржа $2 / 2$

Рис. 1. Различные схемы армирования слоистого композита

риала и выкладка на технологическую оснастку необходимого количества слоёв армирующего материала. В процессе выкладки между заранее определенными слоями укладывается оптическое волокно с небольшим предварительным натяжением, для того чтобы обеспечить прямолинейную ориентацию в процессе дальнейшей полимеризации материала. Необходимо отметить, что наиболее опасными участками являются области ввода и вывода оптического волокна из композитного материала. Для обеспечения целостности волокна рекомендуется обеспечить защиту данных областей с помощью тефлоновых трубок. После выполнения всех вышеупо- мянутых операций проводится режим полимеризации. Более подробно о режиме создания ПКМ, используемого в данном исследовании, можно найти в работе [27].

Для изготовления всех образцов использовался метод прямого прессования. Между слоями композитного материала внедрялось стандартное одномодовое оптическое волокно диаметром 148 мкм (с учетом защитной полиимидной оболочки). Полученные методом прямого прессования образцы из стеклопластика и углепластика были разрезаны на отдельные элементы (рис. 2 и 3) для дальнейшего анализа поперечных сечений с помощью цифрового микроскопа.

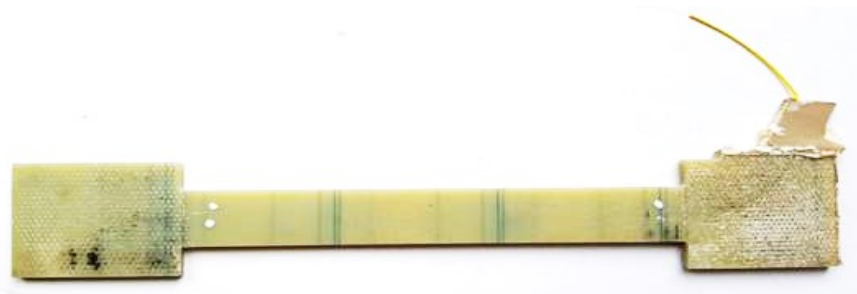

Рис. 2. Образеи из стеклопластика с внедренным оптическим волокном
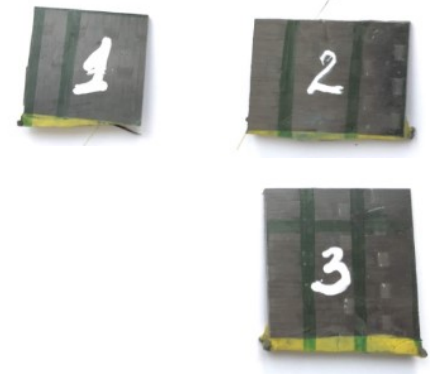

6

$\left[\mathrm{O}_{2} / \mathrm{OF} / \mathrm{O}_{4}\right]$

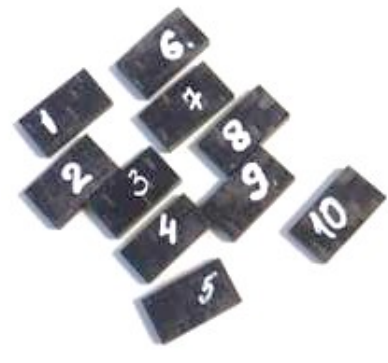

саржа $2 / 2$

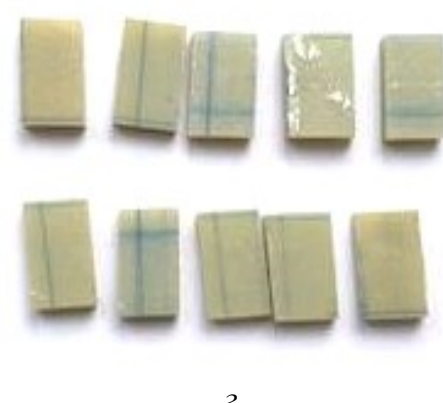

саржа $2 / 2$

Рис. 3. Фотографии образиов слоистого композита с различными схемами армирования, выполненных из углепластика (a, б, в) и стеклопластика (2) 


\section{Однонаправленный уалепластик}

В качестве подтверждения тезиса, описанного в работе [10], о том, что наиболее значительно структура исходного материала искажается при встраивании оптического волокна под углом $90^{\circ}$ к направлению армирования слоев композитного материала, проведен следующий эксперимент. Были созданы и рассмотрены композитные образцы с однонаправленной структурой армирования каждого слоя, фотографии которых представлена на рис. $3, a$ и б. Образец состоит из 6 слоев (материал ВКУ-29). При этом в образце 1 (рис. 3,a) оптоволокно было уложено вдоль направления армирования между слоями 2 и 3 , а в образцах 2 и 3 поперек, т.е. под углом $90^{\circ}$ к направлению армиро- вания слоя, - между слоями 3 и 4. На рис. 4 представлены снимки поверхности сечения образца 1 с различными увеличениями 140x (a); 280x (б), 420x (в). Можно отметить, что при совпадении направления армирования композитного материала с направлением укладки оптического волокна, волокно оказывается плотно встроенным в структуру материала. Каких-либо технологических дефектов не обнаружено.

На рис. 5, 6 представлены снимки поверхности сечения образцов 2 и 3 соответственно с различными увеличениями 140x (a); 280x (б), 420x (в). На снимках явно виден технологический дефект - смоляной карман, образованный вокруг внедренного волокна. Длина смоляного кармана составила порядка 9 диаметров для образ-

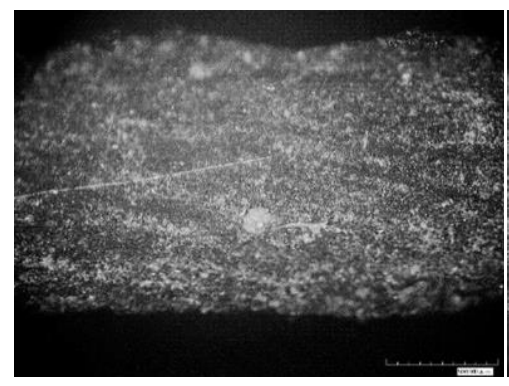

$a$

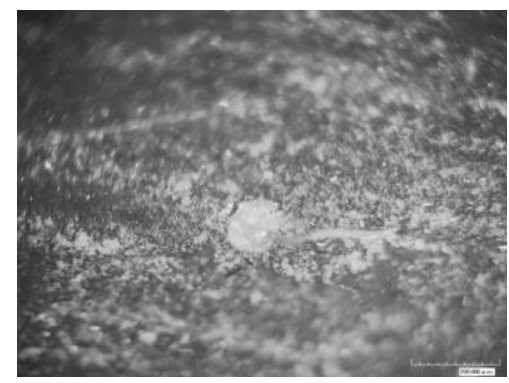

$\sigma$

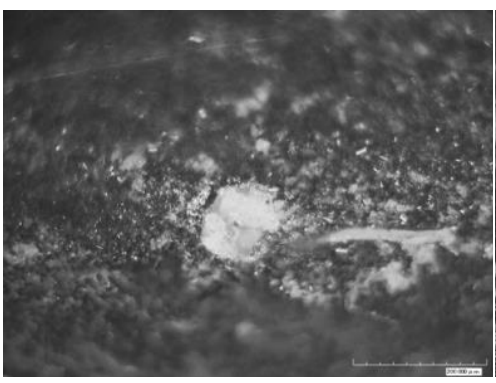

B

Рис. 4. Снимки поверхности сечения образиа 1

с различными увеличениями
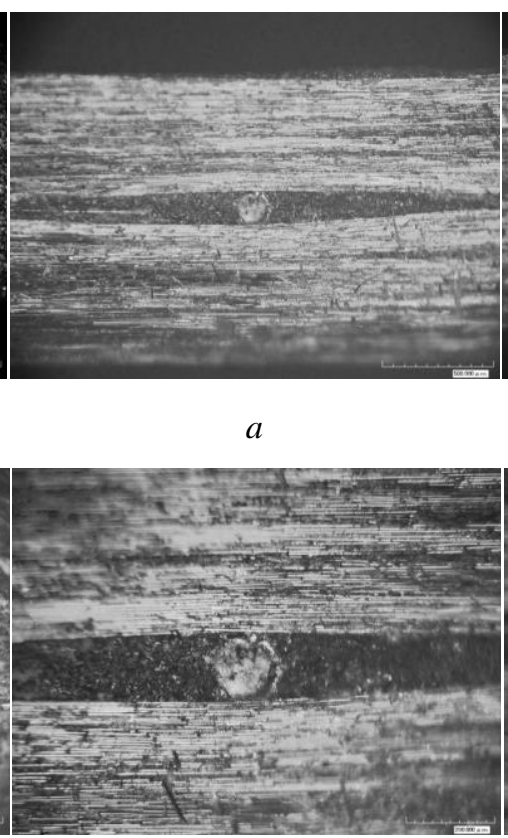

$\sigma$

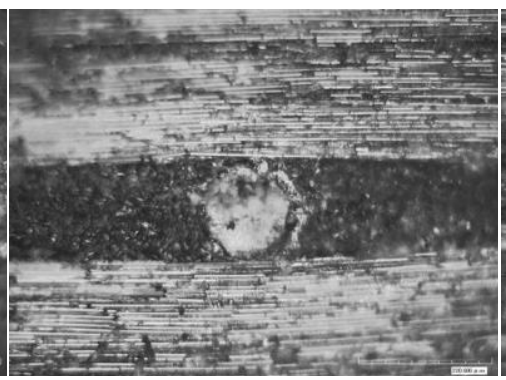

B

Рис. 5. Снимки поверхности сечения образиа 2

с различными увеличениями
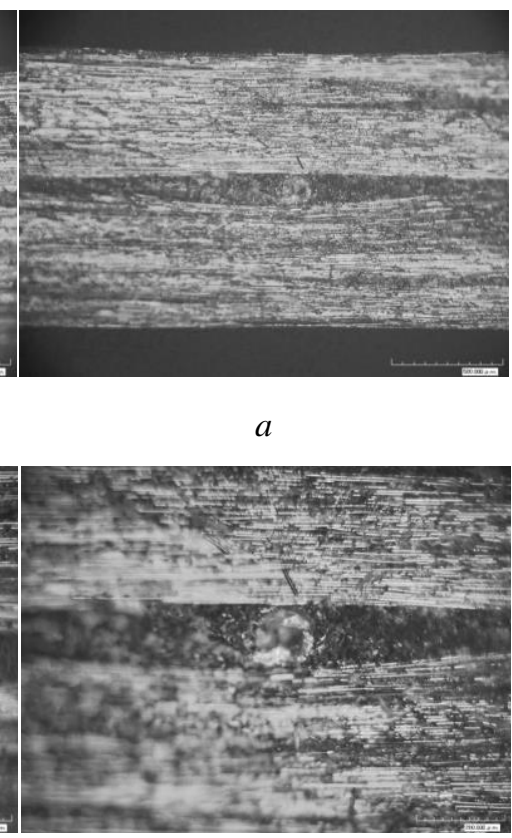

$\sigma$

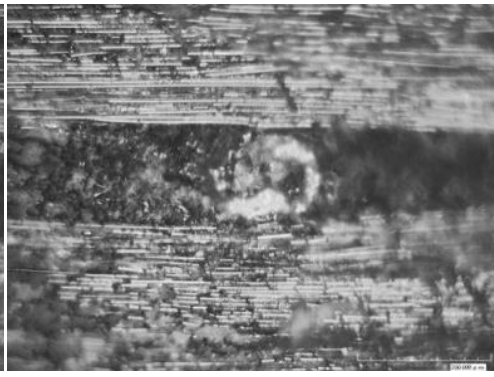

Рис. 6. Снимки поверхности сечения образия 3

с различными увеличениями 
ца 2 и 10 диаметров для образца 3. Однако смоляной карман, образовавшийся в образце 3 , имеет более выраженную асимметрию формы. Также стоит отметить отсутствие зазора между оптическим волокном и слоями композитного материала.

\section{Образцы с плетеной структурой армирования}

Укладка оптических волокон диаметром 0,124 мм с защитной оболочкой из полиимида, толщиной 0,012 мм, производилась между 10-м и 11-м слоями композитного материала с плетеной структурой армирования (рис. 7)

Часть поперечных сечений образцов с внедренными оптическими волокнами была отполирована, а часть оставлена в исходном после разреза состоянии. На рис. 8 приведены изображения полированных и неполированных сечений образов из стеклопластика при 140-кратном увеличении. Для данного типа материала обработка поверхности приводит к лучшей видимости оптического волокна, однако сама структура композитного материала становится менее различима. При отсутствии какойлибо обработки поверхности, в силу неоднородности высоты, возникают сложности в фокусировке микроскопа, однако нити основы и утка материала имеют более четкие границы

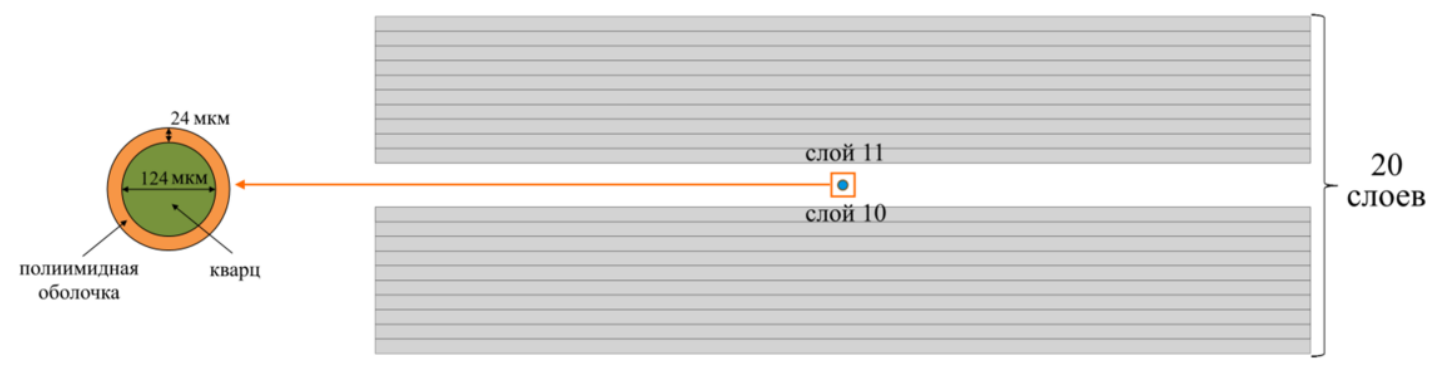

Рис. 7. Схема расположения оптического волокна между слоями композитного материала

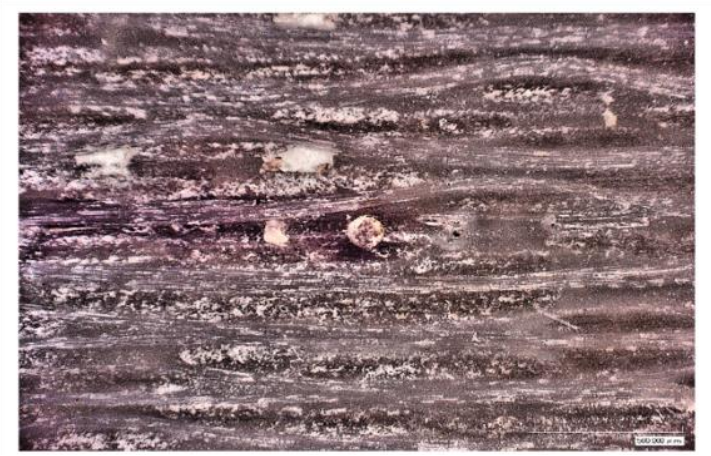

$a$

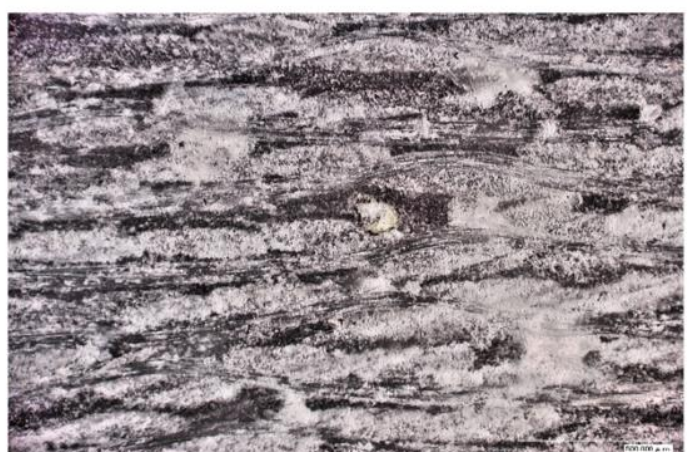

B

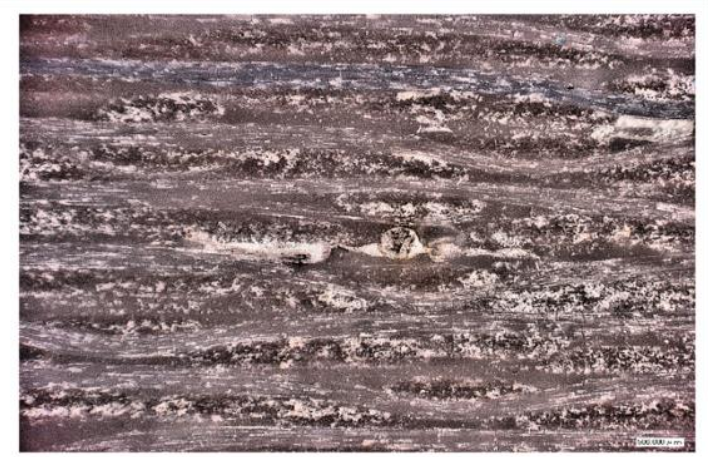

$\sigma$

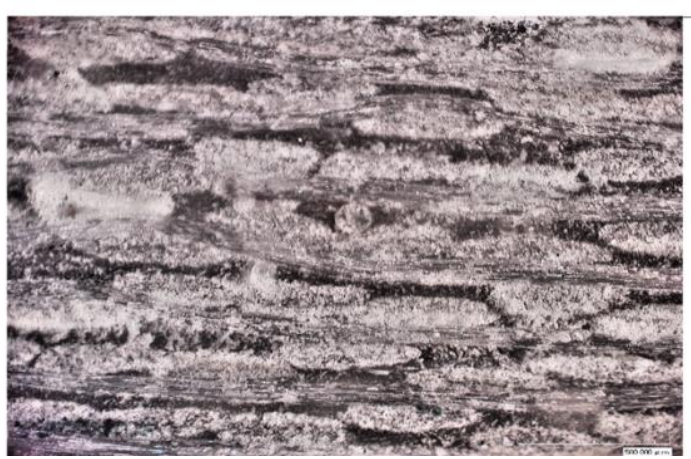

2

Рис. 8. Снимки поперечных сечений образцов из стеклопластика с внедренным оптическим волокном с отполированной поверхностью (а), (б) и в исходном состоянии (в), (2) 
Анализ полученных снимков показал, что на образцах из стеклопластика различимы такие элементы композитного материала, как нити (жгуты) основы и утка, а также области, заполненные связующим (рис. 9). Несмотря на то что оптическое волокно находится в области, заполненной смолой, наблюдается лишь незначительное искривление структуры композитного материала в окрестности внедренного оптического волокна без формирования смоляного кармана. Аналогичные снимки поперечных сечений образцов из углепластика представлены на рис. 10.

В связи с определенными различиями между углеродными волокнами и стекловолокном в физико-химических свойствах, размере и плотности, композитный материал с армированием из углеродного волокна имеет более упорядоченную структуру, в которой при помощи оптического микроскопа не удалось различить индивидуальные нити утка, только основы. В данном случае преимущества полировки

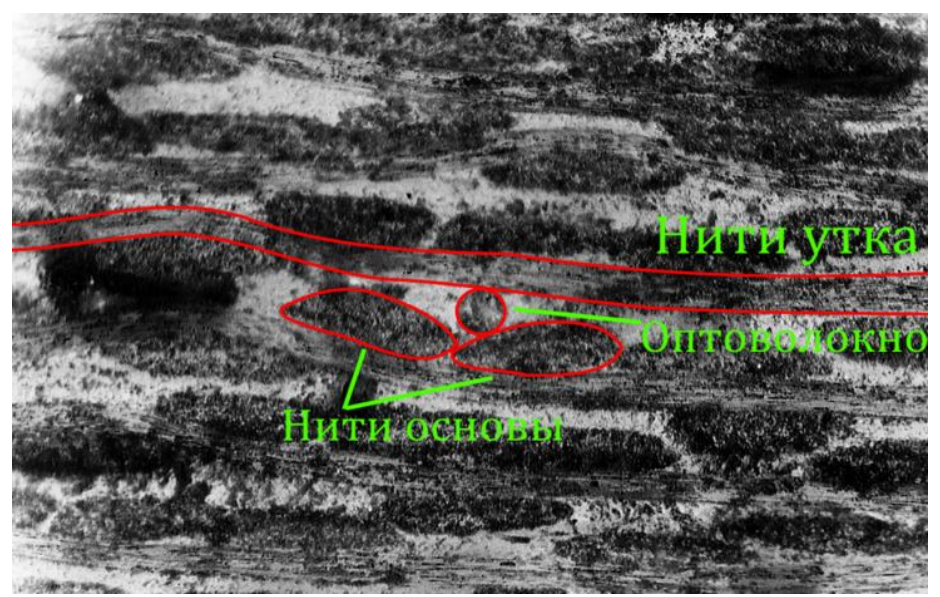

Рис. 9. Снимок внутренней структуры образиа из стеклопластика с плетеной структурой армирования в окрестности внедренного оптического волокна
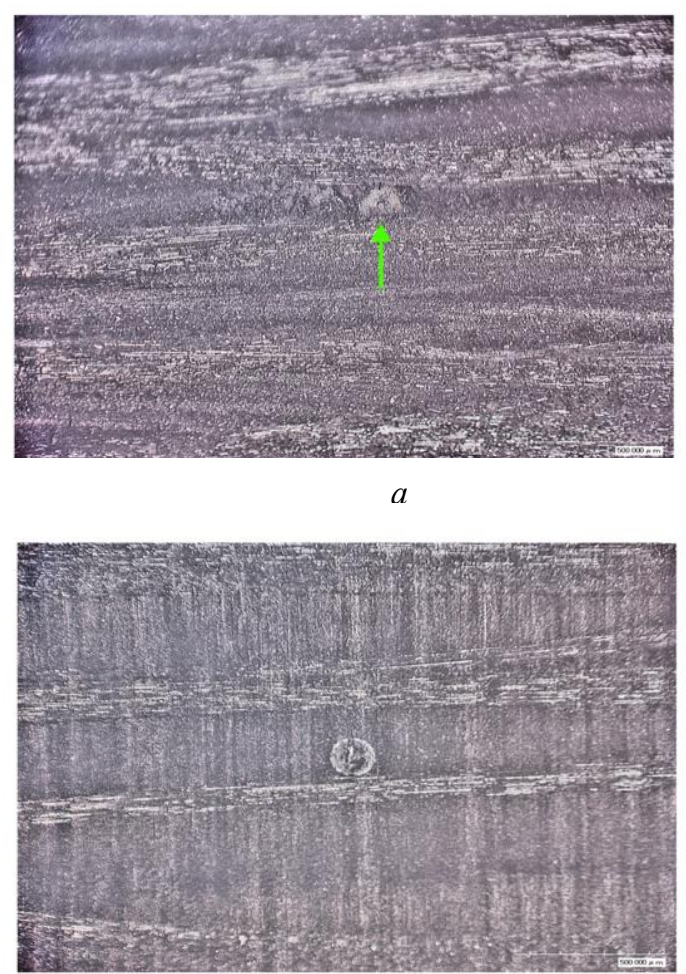

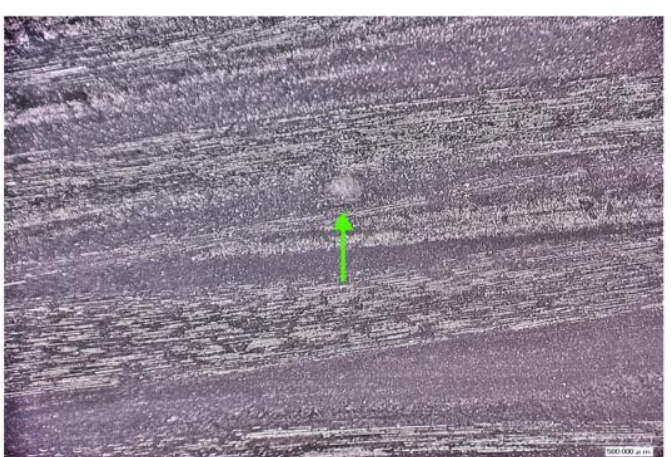

6

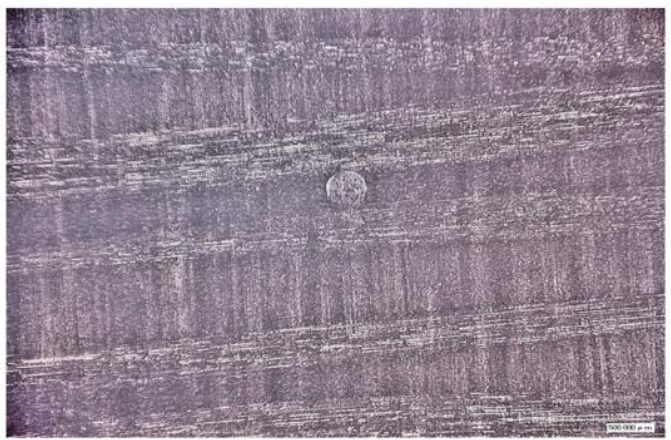

Рис. 10. Снимки поперечных сечений образиов из углепластика с внедренным оптическим волокном с отполированной поверхностью (а), (б) и в исходном состоянии (в), (2) 
поверхности поперечного сечения ярко выражены, так как в ее отсутствии оптическое волокно практически неразличимо. На полученных изображениях не удалось выявить искажений внутренней структуры композитного материала с плетеной структурой армирования в окрестности внедренного оптического волокна.

Наличие смоляного кармана в окрестности внедренного оптического волокна распространено для композитных материалов с однонаправленной структурой армирования и является потенциальным источником появления трещин и расслоений. Отсутствие признаков наличия смоляного кармана для рассмотренных композитных материалов с плетеной структурой армирования указывает на различия во взаимодействии на этапе изготовления образцов между оптическим волокном и внутренней структурой разных типов композитных материалов. Одним из возможных объяснений является то, что в отличие от слоев с однонаправленной структурой армирования, которые изгибаются вокруг оптического волокна при их перпендикулярной ориентации относительно друг друга, отдельные жгуты основы и утка обеспечивают больше свободного пространства для оптического волокна, и таким образом происходит более эффективная интеграция волокна в структуру композитного материала.

\section{Заключение}

Настоящая работа посвящена исследованию влияния встроенного оптического волокна на внутреннюю структуру композиционных материалов. Целью данного исследования являлось расширение знаний по этой проблеме для различных типов композиционных материалов. В отличие от известных исследований, посвященных материалам с однонаправленной структурой армирования, были изучены два типа композитных материалов (стеклопластик и углепластик) с однонаправленной и тканой структурой армирования со встроенным оптическим волокном.На изображениях поперечных сечений исследуемых поли- мерных композиционных материалов с различными видами обработки поверхности были проанализированы структурные изменения, вызванные внедрением оптических волокон. Полировка исследуемой поверхности позволяет более четко различать местоположение оптического волокна в структуре композиционного материала, однако для случая стекловолокна ухудшается видимость структурных составляющих композита. Для образцов композитных материалов из углеродного волокна без полировки обнаружить оптическое волокно практически невозможно. Однако для исследуемых материалов анализ как полированных, так и неполированных поверхностей дает более полную информацию о внутренней структуре материала.

Экспериментально было еще раз показано, что для однонаправленных композитов наиболее значительно структура исходного материала искажается при встраивании оптического волокна под углом $90^{\circ} \mathrm{\kappa}$ направлению армирования слоев композитного материала. При совпадении направления армирования композитного материала c направлением укладки оптического волокна каких-либо технологических дефектов не обнаружено. Анализ структуры не выявил значительных искажений слоев в области внедренного оптического волокна и образования смоляного кармана для рассматриваемых композиционных материалов с тканой армирующей структурой.

Полученные результаты свидетельствуют о перспективности и целесообразности использования встроенных оптических волокон для оценки механического состояния конструкций из композиционных материалов. Однако для построения эффективных и надежных систем мониторинга на основе этой технологии необходимо учитывать такие факторы, как тип и структура армирования композитного материала, в который встроено оптическое волокно, технологический процесс, возможные искажения отраженного оптического сигнала, на основании которого определяются измеряемые физические величины (деформация, температура). 


\section{Библиографический список}

1. Roberts S.S.J., Davidson R. Mechanical properties of composite materials containing embedded fiber-optic sensors // Fiber Optic Smart Structures and Skins IV. - 1991. - Vol. 1588. - P. 326-341.

2. Hadzic R., John S., Herszberg I. Structural integrity analysis of embedded optical fibre in composite structures // Composite Structures.- 1999. - Vol. 47. - № 1-4. - P. 759-765.

3. Jensen D.W., Pascual J., August J.A. Performance of graphite/bismaleimide laminates with embedded optical fibers. I. Uniaxial tension // Smart Materials and Structures.- 1992. - Vol. 1. - № 1. - P. 24-30.

4. Surgeon M., Wevers M. Static and dynamic testing of a quasi-isotropic composite with embedded optical fibres // Composites Part A: Applied Science and Manufacturing.- 1999. - Vol. 30. - № 3. - P. 317-324.

5. Lee D.C., Lee J.J., Yun S.J. The mechanical characteristics of smart composite structures with embedded optical fiber sensors // Composite Structures.- 1995. - Vol. 32. - № 1-4. - P. 39-50.

6. Silva J.M.A., Devezas T.C., Silva A.P., Ferreira J.A.M. Mechanical Characterization of Composites with Embedded Optical Fibers // J. Compos. Mater. - 2005. - Vol. 39. - № 14. - P. 1261-1281.

7. Dasgupta A., Wan Y., Sirkis J.S. Prediction of resin pocket geometry for stress analysis of optical fibers embedded in laminated composites // Smart Materials and Structures.- 1992. - Vol. 1. - № 2. - P. 101-107.

8. Lammens N., Luyckx G., Voet E., Van Paepegem W., Degrieck J. Finite element prediction of resin pocket geometry around embedded optical fiber sensors in prepreg composites // Composite Structures.- 2015. Vol. 132. - P. 825-832.

9. Lammens N., Luyckx G., Van Paepegem W., Degrieck J. Finite element prediction of resin pocket geometries around arbitrary inclusions in composites: Case study for an embedded optical fiber interrogator // Composite Structures.- 2016. - Vol. 146. - P. 95-107.

10. Shivakumar K., Emmanwori L. Mechanics of failure of composite laminates with an embedded fiber optic sensor // Journal of Composite Materials. - 2004. - Vol. 38. - № 8. - P. 669-680.

11. Al-Shawk A., Tanabi H., Sabuncuoglu B. Investigation of stress distributions in the resin rich region and failure behavior in glass fiber composites with microvascular channels under tensile loading // Composite Structures.- 2018. - Vol. 192. - P. 101-114.

12. Singh H., Sirkis J.S., Dasgupta A. Microinteraction of optical fibers embedded in laminated composites // Fiber Optic Smart Structures and Skins IV. - 1991. - Vol. - 1588. - № 1-991 - P. 76-85.

13. Czarnek R., Guo Y.F., Bennett K.D., Claus R.O. Interferometric Measurements Of Strain Concentrations Induced By An Optical Fiber Embedded In A Fiber Reinforced Composite // Fiber Optic Smart Structures and Skins. - 1989. - Vol. 0986. - P. 43.

14. Voet E., Luyckx G., De Waele W., Degrieck J. Multi-axial strain transfer from laminated CFRP composites to embedded Bragg sensor: II. Experimental validation // Smart Materials and Structures.- 2010. - Vol. 19. № 10. - P. 105018.

15. Wagreich R.B., Atia W.A., Singh H., Sirkis J.S. Effects of diametric load on fibre Bragg gratings fabricated in low birefringent fibre // Electronics Letters. - 1996. - Vol. 32. - № 13. - P. 1223.

16. Udd E. Review of multi-parameter fiber grating sensors // Fiber Optic Sensors and Applications V. - 2007. Vol. 6770. - P. 677002.

17. Gafsi R., El-Sherif M.A. Analysis of Induced-Birefringence Effects on Fiber Bragg Gratings // Optical Fiber Technology.- 2000. - Vol. 6. - P. 299-323.

18. Emmons M.C., Carman G.P., Mohanchandra K.P., Richards W.L. Characterization and birefringence effect on embedded optical fiber Bragg gratings // Health Monitoring of Structural and Biological Systems 2009. - 2009. - Vol. 7295. - № March. - P. 72950C.

19. Peters K., Pattis P., Botsis J., Giaccari P. Experimental verification of response of embedded optical fiber Bragg grating sensors in non-homogeneous strain fields // Optics and Lasers in Engineering.- 2000. Vol. 33. - № 2. - P. 107-119.

20. Peters K., Studer M., Botsis J. [et al] Embedded optical fiber Bragg grating sensor in a nonuniform strain field: Measurements and simulations // Experimental Mechanics. - 2001. - Vol. 41. - № 1. - P. 19-28.

21. Huang S., Ohn M. M., LeBlanc M., Measures R.M. Continuous arbitrary strain profile measurements with fiber Bragg gratings // Smart Materials and Structures.- 1998. - Vol. 7. - № 2. - P. 248-256.

22. Makhsidov, V., Fedotov, M., Shiyonok, A., Zuev M. For an issue of embedded optical fibre in CFRP and strain measurement with fibre Bragg gratings sensors // FSUE «All-Russian Scientific-Research Institute of Aviation Materials». - 2014. - Vol. 20. - № 4. - P. 568-574.

23. Majumder M. [et al] Fibre Bragg gratings in structural health monitoring-Present status and applications // Sensors and Actuators A: Physical.- 2008. - Vol. 147. - № 1. - P. 150-164.

24. Gebremichael Y.M., Li W., Boyle W.J.O. [et al] Integration and assessment of fibre Bragg grating sensors in an all-fibre reinforced polymer composite road bridge // Sensors and Actuators A: Physical.- 2005. Vol. 118. - № 1. - P. 78-85. 
25. Matveenko V.P., Shardakov I.N., Voronkov A.A. [et al] Measurement of strains by optical fiber Bragg grating sensors embedded into polymer composite material // Structural Control and Health Monitoring. 2018. - Vol. 25. - № 3. - P. e2118.

26. Di Sante R. Fibre Optic Sensors for Structural Health Monitoring of Aircraft Composite Structures: Recent Advances and Applications // Sensors. - 2015. - Vol. 15. - № 8. - P. 18666-18713.

27. Matveenko V.P., Kosheleva N.A., Shardakov I.N., Voronkov A.A. Temperature and strain registration by fibre-optic strain sensor in the polymer composite materials manufacturing // International Journal of Smart and Nano Materials. - 2018. - Vol. 9. - № 2. - P. 99-110.

\title{
THE INFLUENCE OF EMBEDDED OPTICAL FIBER ON THE INTERNAL STRUCTURE OF POLYMER COMPOSITE MATERIAL
}

Kosheleva N.A., Serovaev G.S.

Institute of Continuous Media Mechanics UB RAS

\begin{abstract}
For citation:
Kosheleva N.A., Serovaev G.S. The influence of embedded optical fiber on the internal structure of polymer composite material // Perm Federal Research Center Journal. - 2021. - № 1. - P. 54-63. https://doi.org/10.7242/2658-705X/2021.1.5
\end{abstract}

In this work the samples made of polymer composite materials with embedded optical fibers were studied. The diameter of the optical fiber is comparable to the thickness of the layer of the composite material. So, the internal structure of the source material may be distorted in the vicinity of the optical fiber because of optical fiber embedment. Consequently, the formation of technological defects poses a threat to the integrity of the source material. Cross-sectional micrographs of various types of composite materials in the vicinity of the embedded optical fiber were obtained in the study. For a unidirectional composite material the formation of a resin pocket when the optical fiber is embedded perpendicular to the direction of the reinforcing fibers and its absence when the optical fiber is embedded parallel to the direction of the reinforcing fibers is confirmed. The analysis of images of woven polymer composite materials with twill weave did not reveal significant distortions of the internal structure of the source material. Recommendations are given for preliminary treatment (polishing) of fiber-glass and carbonfiber reinforced plastic specimen surfaces.

In contrast to the known results on the significant influence of the layering scheme on the efficiency of optical fibers embedment into composite materials, the data obtained in this study also indicate the effect of the material of the reinforcing fibers and the type of reinforcement on the quality of embedding optical fibers. These factors should be considered when designing and creating structures with embedded fiber-optic sensors.

Keywords: polymer composite material, optical fiber, fiber-optic strain sensors, microstructure, resin pocket.

\section{Сведения об авторах}

Кошелева Наталья Александровна, кандидат технических наук, научный сотрудник, Институт механики сплошных сред УрО РАН - филиал Пермского федерального исследовательского центра УрО РАН («ИМСС УрО РАН»), 614013, г. Пермь, ул. Академика Королева, 1; e-mail: kosheleva.n@icmm.ru

Сероваев Григорий Сергеевич, младший научный сотрудник, «ИМСС УрО РАН»; e-mail: serovaev@icmm.ru 